\title{
L-BAND AND C-BAND INSAR STUDIES OF AFRICAN VOLCANIC AREAS
}

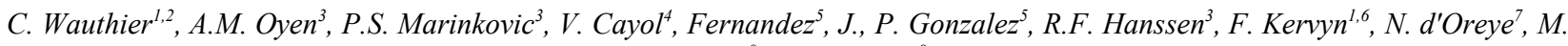 \\ Shirzaei ${ }^{8}$, T. R. Walter ${ }^{8}$
}

\begin{abstract}
${ }^{1}$ Dept. of Geology, Royal Museum for Central Africa, 3080 Tervuren, Belgium, christelle.wauthier@africamuseum.be $/{ }^{2}$ Dept. ArGEnCo,University of Liège, Sart Tilman B52, 4000 Liège, Belgium $/{ }^{3}$ Delft Inst. of Earth Obs. and Space Systems, Delft Univ. of Tech., 2629HS Delft, The Netherlands $/{ }^{4}$ Lab. Magmas et Volcans, Université Blaise Pascal - UMR 6524, 63038 Clermont-Ferrand, France $/{ }^{5}$ Instituto de Astronomia y Geodesia (CSIC-UCM), Plaza de Ciencias, 28040 Madrid, Spain / ${ }^{6}$ Centre d'Informations Géographiques SODERU, Goma, North-Kivu, DRC $/{ }^{7}$ Dept. of Geophysics/Astrophysics, National Museum of Natural History, Luxembourg $/^{8}$ GeoForschungsZentrum (GFZ), VolcanoTectonics Junior Research Group, 14473 Potsdam, Germany
\end{abstract}

\begin{abstract}
Radar interferometry has proven to be a very suitable, low-cost and accurate tool to measure surface displacements. We investigate several data fusion or time-series analysis strategies which aim to mitigate C-band InSAR restrictions for volcano deformation monitoring applications. The focus is on active African volcanic areas. Firstly, data fusion of C-band ENVISAT/ASAR and L-band ALOS/PALSAR sensors helps the determination of a rifting event sequence that took place in summer 2007 in Lake Natron area. The second strategy investigated is a new Wavelet Based InSAR time series applied on ERS-2 data covering the NyiragongoNyamulagira area. It allows new ground displacements identifications outside the local rift valley. Lastly, PALSAR QuadPol POLInSAR applicability is explored for La Palma Island.
\end{abstract}

Index Terms - Radar interferometry, numerical modeling, volcano monitoring, East African Rift.

\section{INTRODUCTION}

Study and monitoring of active volcanic areas in Africa can be problematic using ground-based methods, due to political tensions, security problems or difficult field accessibility. Remote-sensing techniques, particularly C-band Differential Synthetic Aperture Radar Interferometry (DInSAR), are therefore very useful, and provide robust observational tools for hazard assessment. Although well known C-band DInSAR suffers from vegetation-induced temporal decorrelation [1], as commonly encountered in equatorial regions and fertile volcanoes. In such a context, the minimal 35 days revisiting time, and the few tens of meters resolution, of current C-band satellites does not allow to overcome all the decorrelation problems. In case of strong deformation events, spatial aliasing can lead to decorrelation and prevent reliable unwrapping. Tropospheric effects, turbulent or stratified with topography, can also notably contaminate $\mathrm{C}$ and L-band InSAR signals. Ionospheric effects can furthermore be an issue in L-band InSAR, but was specially observed for high latitudes areas.

Considering all these restrictions, the following research question can be raised: how to mitigate restrictions, as imposed by C-band InSAR for the volcano deformation monitoring applications? In the following, we try to answer this question by investigating different data fusion or time-series analysis strategies. Firstly, by using $\mathrm{C}$ and L-band sensors data, and later by time- series analysis on data from a single $\mathrm{C}$-band sensor. The focus, is in particular on African volcanic areas.

\section{METHODOLOGY}

Specifically, three strategies for data fusion of C and L-band sensors, or time-series analysis on data from a single $\mathrm{C}$-band sensor are presented:

Firstly, as proposed in [2], the optimization of unwrapping and modeling was performed. The unwrapping optimization utilizes the unwrapped L-band data as a priori information to condition the unwrapping of less coherent C-band interferograms that cover a similar time span. While, the modeling optimization is realized through the decomposition of complex interferograms covering long temporal baselines. This optimization will be discussed in detail in Section 3.1.

A second strategy, which aims at the combination of time series analysis derived from different acquisition geometries, is applied. It is chosen to apply a new Wavelet Based InSAR time series (WAB-InSAR) [3]. This technique allows removing of DEM, orbital and atmospheric errors from the InSAR signal.

Finally, the applicability of POLInSAR with Quad-Pol ALOS data is explored. The goal is to take advantage of polarization synthesis capabilities in order to find transmit and receive polarization scheme that allows optimizing the interferometric signal for each resolution element.

All interferometric processing was performed with opensource and freely available tools, namely: DORIS, ROI-PAC, and POLSARPRO.

\section{CASE STUDIES}

The evaluation of the proposed strategies was performed on the following volcanic areas in Africa: the Lake Natron, the Nyiragongo-Nyamulagira, and La Palma Island.

\subsection{Lake Natron area}

The Natron basin, located in the eastern branch of the East African Rift (EAR) in Northern Tanzania, was struck by a seismic crisis in July-August 2007, culminating in a Mw 5.9 event on July 17th. This continental rifting event was captured by both the ENVISAT/ASAR and ALOS/PALSAR sensors.

Eight interferograms covering the 2007 seismic event are selected (Fig.1). This selection is based on the presence of 
displacements and on the coherence level. The C-band interferograms reveal complex episodes and associated ground displacement patterns [4]. The large number of fringes is in some particular places affected by vegetation-induced decorrelation, which complicates the phase unwrapping, interpretation, and deformation modeling [2,4]. Two L-band interferograms provide extra data that help interpreting the displacements. Moreover, they help to constrain the chronology of the complex sequence of events.

First, the unwrapping optimization is performed on the interferograms containing ambiguity cycle slips. The correction, which is applied to those interferograms, is derived from a combination of the correct unwrapped interferograms and the field measurements [5].

When the unwrapped interferograms are corrected, the modeling optimization is applied. Specifically, multiple events are decomposed into individual, tectonic or magmatic, events through the modeling of interferograms that cover short temporal baselines. Then, by means of the numerical 3D Mixed Boundary Element models [6], artificial C and L-band interferograms can be created and subtracted from the long temporal baselines interferograms. Note, that the numerical modeling method takes into account realistic topographies as well as any number and geometry of faults and pressure sources located in a linear, elastic and homogeneous medium. In order to determine the most likely sources parameters, this method is combined with a near-neighbourhood inversion algorithm [7]. As boundary conditions tractions were used, with null values on the ground surface and equal to constant overpressures for dikes and constant shear stress drops for faults. Due to the complexity of the observed phenomena, some assumptions need to be made in order to reduce the number of parameters to invert. In the first place, dikes are assumed to be subvertical (consistent with the rift context) and located at the central axis of the graben, which is marked by surface ruptures south of the Gelai volcano. The geometry of the Graben Bounding Faults (GBFs) is fixed according to the field measurements [5] and literature [8]. Consequently, the distance below the Earth's surface and the top of the dike is predefined by the depths of the GBFs. Finally, buried normal faults are modeled with a fixed shear stress drop of $3 \mathrm{MPa}$. The modeling optimization results, detailed in [2], show that the sequence begins (part I in Fig.1) with a $1.35 \mathrm{~m}$ slip along a long buried west-dipping fault. Part II of the swarm, covering the diking episodes, is mainly modeled by a dike triggering a slip along GBFs. Additionally, two fault movements were modeled, both in the direction of the migration of the dike intrusions (north- and southwards respectively). Finally, part III of the swarm is modeled by slip along two east-dipping faults reaching the surface on the southeastern flank of the Gelai volcano.

\subsection{Nyiragongo-Nyamulagira area}

The Nyamulagira and Nyiragongo are two active volcanoes of North Kivu (Dem. Rep. of Congo). They are located in the western branch of the EAR, an area affected by a combination of tectonic and volcanic activities. In this area, C-band InSAR strongly suffers from vegetation induced decorrelation. When ground displacements occurred in the area, they can be missed or only partially captured by C-band InSAR. We have a large database of
SAR images covering volcanic or tectonic events in this area from 1996, acquired from the JERS, ERS, ENVISAT, RADARSAT and ALOS satellites.

The low coherence in the C-band interferograms covering both volcanoes is a big issue due to the high decorrelation rate induced by the equatorial vegetation covering most of the area. Only the C-band interferograms having small temporal and perpendicular baselines are usable, even if some areas remain incoherent like the vegetated slopes of volcanoes and the area outside of the rift. Considering the 2002 eruption, a simultaneous study [9] shows the advantages of simultaneously using the three C-band InSAR datasets available. In order to improve the analysis of this eruption a combined modeling and inversion procedure is applied.

We also investigated the new WAB-InSAR technique on ERS-2 data. Displacements of Permanent scatters, PS, obtained for the period following the 2002 event, spanning 13 February 2002 to 29 January 2003 are shown in Fig.2. Several areas are affected by ground motions with a maximum of $4.7 \mathrm{~cm}$ range decrease, west of the Western border fault of the rift. This displacement, which is possibly associated to a post-rifting displacement, is not visible in the original ERS-2 and RADARSAT interferograms. Unfortunately, only a few PS are found in the close neighborhood of the two volcanoes but many PS are found outside the rift valley and can therefore be studied by such a method. Results for the ERS-2 data time-series show also that PS outside the rift valley are affected by motion. Unfortunately, at this point, the number and quality of the ERS-2 data only do not allow further interpretations.

Nyamulagira is Africa's most active volcano with an average eruption rate every other year. However, only two out of the six Nyamulagira eruptions were successfully studied by InSAR since the launch of ERS-1. The 2006 Nyamulagira eruption was clearly captured by ENVISAT C-band interferograms (Fig. 3a) because this unusual eruption created a huge deformation pattern, extending to the coherent areas (see [10] for a detailed study). The other eruption capture occurred in 2002 and has a more usual displacement pattern located on the northern flank. Crucial information is therefore lacking because most of the area surrounding the volcano is densely vegetated. L-band InSAR with the JERS satellite already shows better correlation on the dense vegetated flanks of the volcano, and enables to capture displacements at the northern flank caused by the 1996 Nyamulagira eruption (Fig. 3b). The present L-band ALOS interferograms do not show any displacements. However, the coherence is much better compared to C-band or even L-band JERS interferograms (Fig. 3a-b). The ALOS interferogram with a perpendicular baseline inferior to about $700 \mathrm{~m}$, as shown in Fig.3c, has a coherent signal over almost the whole scene.

\subsection{La Palma island}

La Palma in the Canary Islands (Spain) is an active volcanic area. This area is monitored by $\mathrm{C}$-band InSAR satellites such as ERS and ENVISAT. Several areas in La Palma Island are covered by dense vegetation. After two to three acquisition cycles, even for interferograms with small perpendicular baselines, coherence is only maintained in areas covered by recent lava flows [11]. The ALOS/PALSAR sensor can therefore bring information missing 

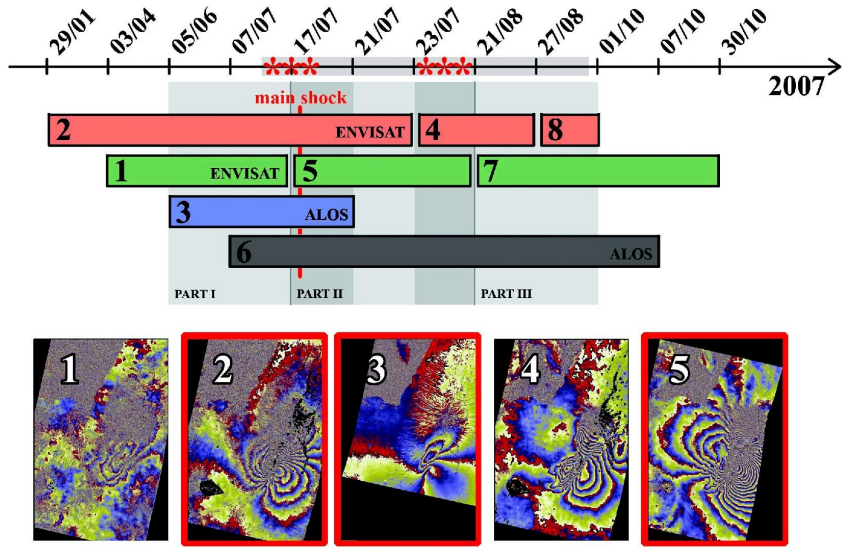

E(26613-28116) E(25697-28202) $\mathrm{Bt}=105$ $\mathrm{Bp}=\mathbf{- 8 7 . 7}$ $\mathrm{Ha}=\mathbf{2 1 5 . 7}$ $\begin{aligned} B t & =175 \\ B p & =-28.5\end{aligned}$ $\mathrm{Ha}=\mathbf{2 7 8 . 3}$

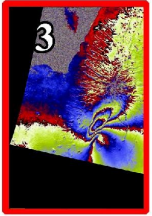

A(07253-07924) $\mathrm{Bt}=46$ $\mathrm{Bp}=-\mathbf{5 4 4 . 1}$ $\mathrm{Ha}=\mathbf{1 1 7 . 9}$

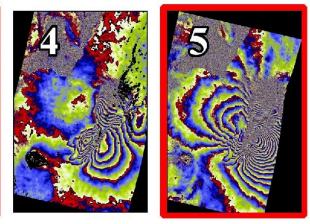

E(28202-28703) E(28116-28617) $\begin{array}{ll}\mathrm{Bt}=35 & \mathrm{Bt}=35\end{array}$ $\mathrm{Bp}=-\mathbf{3 4 . 7} \quad \mathrm{Bp}=-\mathbf{1 2 2 . 9}$ $\mathrm{Ha}=\mathbf{2 2 8 . 5} \quad \mathrm{Ha}=148.7$

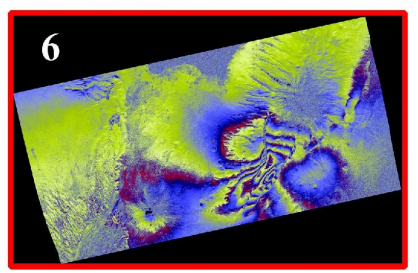

A(07727-09069) $\quad \mathbf{B p}=-250.8$ $\mathrm{Bt}=\mathbf{9 2} \quad \mathrm{Ha}=\mathbf{2 5 6 . 1}$

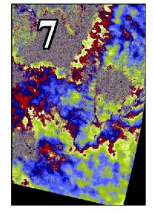

E(28617-29619) E(28703-29204) $\mathrm{Bp}=126.9 \quad \mathrm{Bp}=75.3$ $\begin{array}{ll}\mathrm{Bt}=70 & \mathrm{Bt}=\mathbf{3 5}\end{array}$

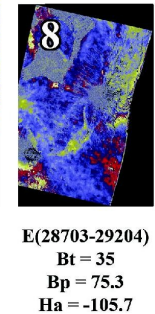

Fig. 1: Summary of the differential interferometric data covering a period from the 29th of January 2007 to the 30th of October 2007 period. Bars in green indicate the ENVISAT track 6 (swath is6) interferograms, bars in red are for the ENVISAT track 92 (swath is2) interferograms. The descending and ascending ALOS interferograms are represented by blue and black bars, respectively. The interferograms are named by their respective orbit numbers and some important parameters, like temporal baseline (Bt), perpendicular baseline $(\mathrm{Bp})$ and height ambiguity $(\mathrm{Ha})$ are listed below each interferogram. Mw $>5$ earthquakes of the seismic swarm, that started in the beginning of July 2007 and lasted up to Sept. 2007, are indicated by the red stars on the time line. More specifically, the main shock is indicated by the vertical red line in the time line. Interferograms 2, 3, 5 and 6 which contain this main shock are outlined by red boxes. Duration of the seismic swarm is indicated by a gray box on the time line. We divided the sequence in three parts referred as part I, II and III.

with C-band monitoring. The new L-band ALOS interferograms calculated for this island show very good coherence on the whole island for perpendicular baselines inferior to about 700 meters, even for larger time spans up to one year. Furthermore, we have a couple of full polarimetric Quad-Pol images covering the southern part of the island. This couple was studied by means of the POLInSAR technique. Coherences obtained for the $\mathrm{HH}$ polarization mode (classic mode used in interferometry) and the best optimized coherence [12] are shown in Fig.4. The optimized coherence histogram on the island is clearly narrowed by the optimization procedure and the distribution peak shifted towards

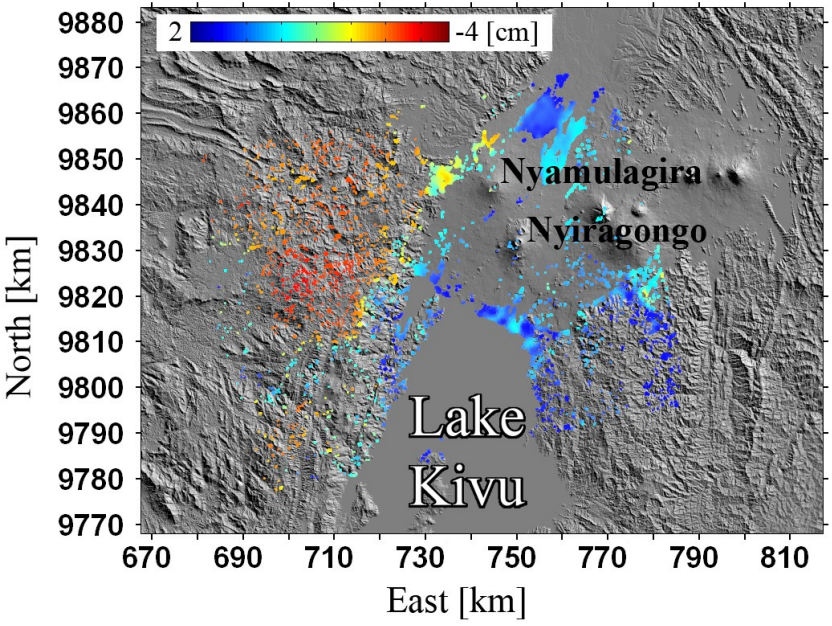

Fig. 2: WAB-InSAR time series applied on ascending ERS-2 data. Unwrapped displacements are in $\mathrm{cm}$ for the 13th of February 2002 to the 29th of January 2003 period.

higher coherence values (from about 0.2 to 0.5 ). The corresponding optimized phase signal is therefore improved. However, this gain is of limited interest regarding volcano monitoring applications in this area. Classic HH L-band ALOS InSAR already offers fully satisfactory coherent interferograms with higher resolution.

\section{CONCLUDING REMARKS AND PERSPECTIVES}

We show in this paper different promising data fusion or timeseries analysis strategies which aim to mitigate restrictions, as imposed by C-band InSAR for the volcano deformation monitoring applications.

Data from several SAR sensors and modes were combined in order to study the tectonic or volcanic deformation associated to the Natron crisis yielding a better determination of the sequence of events that took place from beginning of July until September 2007.

Considering the Nyiragongo-Nyamulagira area, the use of Lband data allows to study most of the area. Additionally, new important ground displacements are captured. The ALOS Systematic Observations ensure a global coverage and thanks to the larger radar wavelength overcome a major part of the temporal decorrelation problems encountered with the C-band satellites. To improve our C-band data (ERS, RADARSAT and ENVISAT), i.e. get information even in vegetated areas and study slow motion events, we propose to apply time-series techniques. This is currently only done for the ERS-2 database. Obviously, such techniques will also be applied on ALOS data once the number of images will be sufficient.

Initial results, obtained from Quad-Pol data and the POLInSAR technique, are potentially interesting in order to improve phase signal quality as shown for La Palma Island. However, the Quad-POL data have worse resolution than the other PALSAR products and the gain is not really a surplus value in our applications. Unfortunately, PALSAR full polarimetric mode is an experimental mode, the available number of Quad-POL images is 

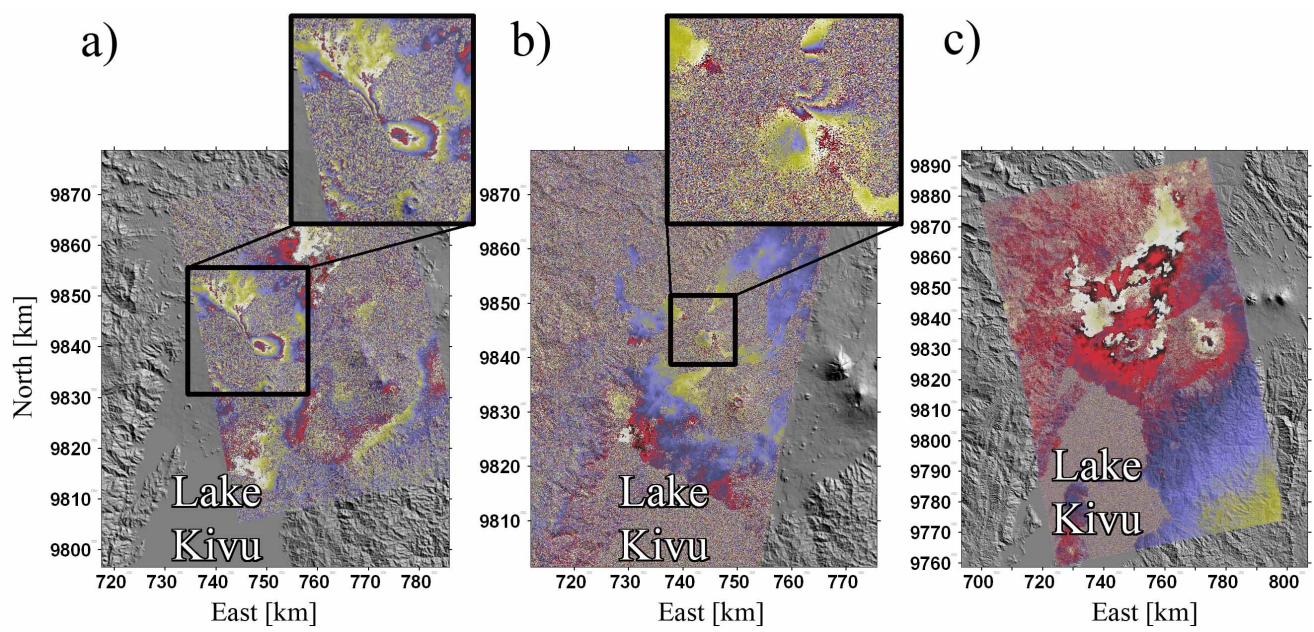

Fig. 3: Comparison of three interferograms covering the Nyamulagira-Nyiragongo area. From left to right: (a) ENVISAT C-band ascending interferogram spanning the 2006 eruption, $\mathrm{Bp} \sim 197 \mathrm{~m}$, inc. ang. $\sim 44^{\circ}, \mathrm{Bt} \sim 1$ month. The inset shows the displacement field on the slopes of the Nyamulagira volcano. (b) JERS L-band descending interferogram spanning 1996 eruption, Bp $\sim 152 \mathrm{~m}$, inc. ang. $\sim 34^{\circ}$, $\mathrm{Bt} \sim 4$ months. The inset shows the displacement field on the northern flank of the Nyamulagira volcano. (c) ALOS L-band ascending interferogram spanning no particular event. No clear deformation is visible. Bp $\sim 400 \mathrm{~m}$, inc. ang. $\sim 34^{\circ}$, Bt $\sim 3$ months. Coherence of the ALOS interferogram is clearly better than for the other interferograms over the whole area.

therefore limited, especially for African areas. Therefore, the monitoring of these area by means of Quad-Pol POLInSAR on a regular basis is currently impossible. Applying the POLInSAR technique to C-band Quad-Pol data is expected to provide better results compared to traditional InSAR, as C-band InSAR suffers strongly vegetation-induced decorrelation. For instance, the RADARSAT-2 satellite has a non-experimental full polarimetric mode.

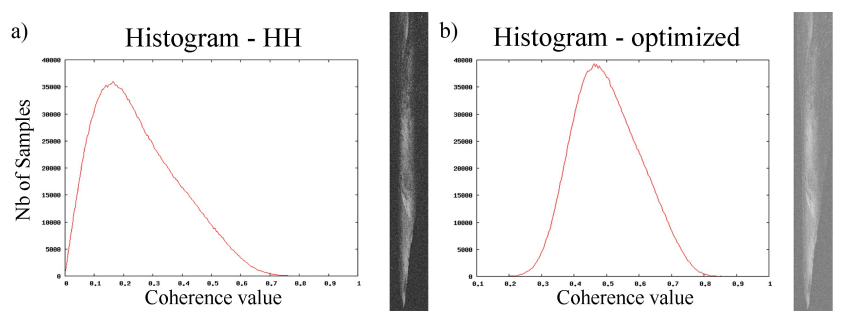

Fig. 4: Coherence distributions and images for South of La Palma Island: a) $\mathrm{HH}$ classic polarization mode and b) Optimized coherence.

\section{REFERENCES}

[1] R.H. Hanssen, 2001, Radar Interferometry - Data interpretation and error analysis, Kluwer Academic Publishers, The Netherlands, $171 \mathrm{p}$.

[2] A. Oyen et al., "A continental rifting event in Tanzania revealed by ENVISAT and ALOS InSAR observations", Proc. of the ALOS PI Symposium 2008, Rhodes, Greece, 2008.
[3] M. Shirzaei and T.R. Walter, 2009, "Deformation interplay at Hawaii Island", Science (submitted).

[4] E. Calais et al., "Strain accommodation by slow slip and dyking in a youthful continental rift, East Africa", Nature, Macmillan Publishers Limited, Vol. 456, pages 783-787, 2008.

[5] D. Delvaux, et al., "Surface structures related to the July 2007 Natron dyking event", N-Tanzania, Tectonic Studies Group meeting, Keele, January 6-8 2009.

[6] V. Cayol, Cornet F.H., "3D mixed boundary elements for elastostatic deformations fields analysis", Int. J. Rock Mech. Min. Sci.Geomech. Abstr., 34, 275-287, 1997.

[7] M. Sambridge, 1999a, "Geophysical inversion with a neighbourhood algorithm - I. Searching a parameter space", Geophys. J. Int., 138, 479-494.

[8] J. Angelier et al., 1997, "Effective tension-shear relationships in extensional fissures swarms, axial rift zone of northeastern Iceland", Journal of Structural Geology, 19, 673-685.

[9] C. Wauthier et al., "The January 2002 eruption of Nyiragongo volcano (DRC) captured by InSAR", IGARSS09 Proceedings (submitted).

[10] V. Cayol et al., "InSAR displacements associated to the November 2006 Nyamulagira eruption", Poster Session TUP.C: Geological Applications III, Thuesday, July 14, 12:40 - 14:20.

[11] Perlock P.A. et al., 2008, Time evolution of deformation using time series of differential interferograms: Application to $\mathrm{La}$ Palma Island (Canary Islands), Pure and Applied Geophysics, 165, $\mathrm{n}^{\circ} 8,1531-1554$.

[12] S.R. Cloude and K.P.Papathanassiou, 1998, "Polarimetric SAR interferometry", IEEE trans. on geoscience and remote sensing 36-5. 